\title{
Photodegradation of HCFC-22 Using Microwave Discharge Electrodeless Mercury Lamp with $\mathrm{TiO}_{2}$ Photocatalyst Balls
}

\author{
Seong-Gyu Seo, ${ }^{1}$ Young-Kwon Park, ${ }^{2}$ Sun-Jae Kim, ${ }^{3}$ Heon Lee, ${ }^{4}$ and Sang-Chul Jung ${ }^{4}$ \\ ${ }^{1}$ Department of Environmental System Engineering, Chonnam National University, Yeosu 550-749, Republic of Korea \\ ${ }^{2}$ School of Environmental Engineering, University of Seoul, Seoul 130-743, Republic of Korea \\ ${ }^{3}$ Faculty of Nanotechnology and Advanced Materials Engineering, Sejong University, Seoul 143-747, Republic of Korea \\ ${ }^{4}$ Department of Environmental Engineering, Sunchon National University, Sunchon 540-742, Republic of Korea
}

Correspondence should be addressed to Sang-Chul Jung; jsc@sunchon.ac.kr

Received 24 November 2013; Revised 26 December 2013; Accepted 9 January 2014; Published 6 March 2014

Academic Editor: Maria Dolores Murcia

Copyright (C) 2014 Seong-Gyu Seo et al. This is an open access article distributed under the Creative Commons Attribution License, which permits unrestricted use, distribution, and reproduction in any medium, provided the original work is properly cited.

\begin{abstract}
The photodegradation of chlorodifluoromethane (HCFC-22) was investigated using microwave/UV/TiO 2 photocatalysts hybrid system. The microwave discharge electrodeless mercury lamp (MDEML) used in this study showed mainly atomic Hg emission lines at $253.7 \mathrm{~nm}$. The decomposition efficiency of HCFC-22 increased with decreasing inlet concentration and with increasing reactor residence time. The removal efficiency increased with increasing microwave power on every oxygen concentration. The highest degradation efficiency was obtained when both $\mathrm{TiO}_{2}$ balls and MDEML were used.
\end{abstract}

\section{Introduction}

Chlorofluorocarbons (CFCs) and hydrochlorofluorocarbons (HCFCs), once widely used as solvents and refrigerants, have been found to be the main culprit for the destruction of the ozone layer [1]. HCFCs have been developed as alternatives to CFCs. HCFCs have shorter lifetime in atmosphere than CFCs and hence smaller ozone depletion potential $[2,3]$. Nevertheless the destruction of waste HCFCs is requested because of their greenhouse effect $[3,4]$ and a certain ozone depletion effect. Application of photolysis for CFC control has recently been investigated widely. Photolysis by short wavelength UV is one of the proposed methods for the destruction of CFC [5].

Advanced oxidation process (AOP) is an advanced gaseous contaminants treatment process, in which highly disinfective and oxidative special ions ( ${ }^{\circ} \mathrm{OH}$ radicals) are produced as intermediate products and are then used to oxidize air pollutants [6]. In addition, the application of $\mathrm{TiO}_{2}$ photocatalysts in AOP air pollution treatment has been widely investigated [7]. Its excellent properties, such as inertness, chemical and thermal stability, regeneration, and low cost, have made it a principal candidate in environmental remediation $[8,9]$. In many photodecomposition reaction systems, $\mathrm{TiO}_{2}$ powders are often used as photocatalysts [10]. However, powder catalysts have several problems, such as the difficulty in separating the catalyst from the suspension after the reaction and preventing catalyst aggregation in high concentration suspensions; the suspension must be diluted to avoid such agglomeration. These problems can be solved with the use of immobilized (i.e., coated) catalyst particles. However, coated catalysts are easily detached from the supports. To avoid these problems, $\mathrm{TiO}_{2}$ thin films have been prepared via the sol-gel [11], sputter [12], and chemical vapor deposition (CVD) methods [13, 14]. Of these, CVD is considered as a promising method for the preparation of high-quality thin films with a well-controlled composition and low defect density over a large surface area $[15,16]$.

Microwave energy has been increasingly used in synthetic organic chemistry because of its capacity to accelerate reactions and to improve yields and selectivity [17]. There is growing interest in using microwave radiation to drive or otherwise assist chemical reactions. Various types of organic and inorganic reactions, once performed using classical heating methods, are now routinely performed using microwave radiation [18]. Recently, research has been conducted actively 


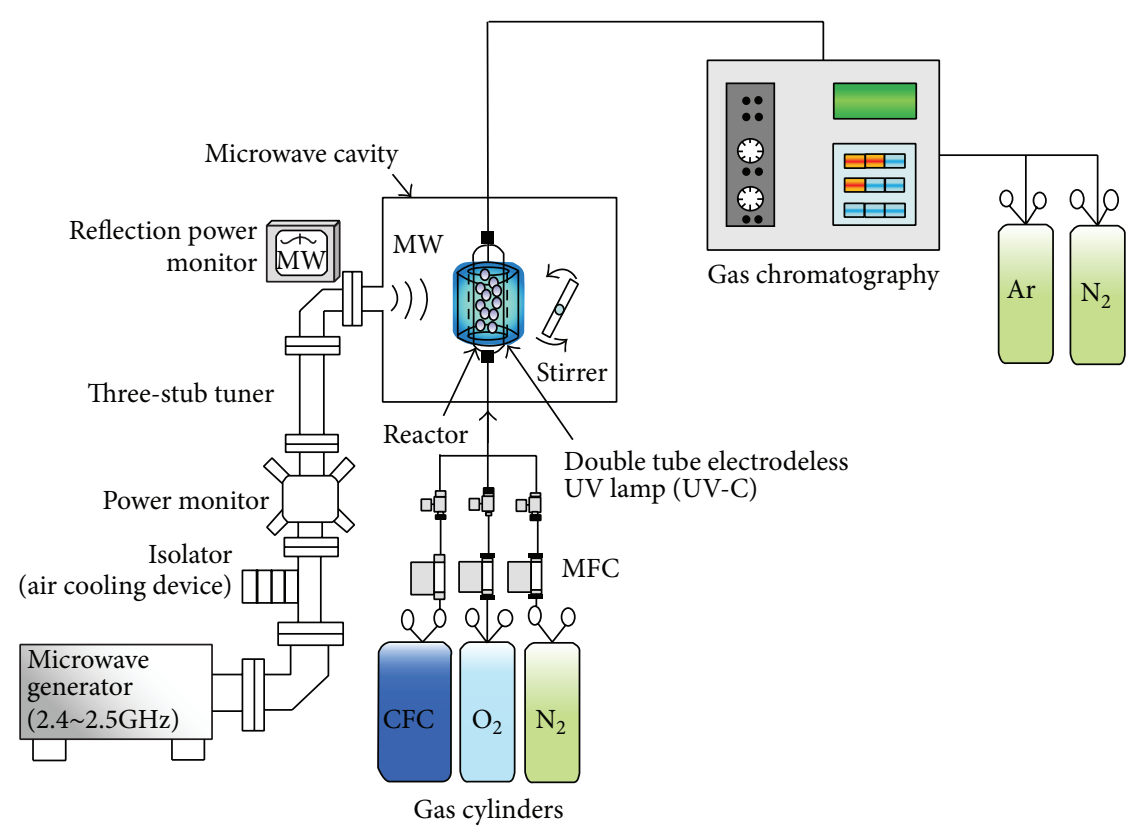

FIgURE 1: The schematic of microwave/UV/ $\mathrm{TiO}_{2}$ photocatalysts hybrid system.

to improve oxidative degradation performance by adding microwave irradiation as an effort to utilize $\mathrm{TiO}_{2}$ photocatalyst treatment more efficiently $[19,20]$.

A double tube type microwave discharge electrodeless mercury lamp (MDEML) that emits UV upon the irradiation of microwave was developed and has been applied to photocatalytic decomposition of various pollutants [21, 22]. In this paper, the MDEML was employed to investigate the photocatalytic decomposition of chlorodifluoromethane (HCFC22 ), an important greenhouse gas. In addition, the advantages of microwave/UV/TiO 2 photocatalysts hybrid process were analyzed. The removal performance was examined under different conditions with different initial HCFC-22 concentrations, gas residence times, and oxygen concentrations.

\section{Experimental}

2.1. Microwave/UV/TiO 2 Photocatalysts Hybrid System. Figure 1 shows the schematic of the microwave/UV/ $\mathrm{TiO}_{2}$ experimental apparatus used in this study. It consists of microwave irradiation equipment, an MDEML, a quartz reactor tube (230 $\mathrm{mm}$ length, $40 \mathrm{~mm}$ diameter) in which photodegradation of HCFC-22 gas takes place, and a gas flow control system using a mass flow controller. The microwave irradiation equipment was manufactured by Korea microwave instrument Co., Ltd. It consisted of a microwave generator (frequency, $2.45 \mathrm{GHz}$; maximal power, $1 \mathrm{~kW}$ ), a three-stub tuner, a power monitor, and a reaction cavity. Microwave radiation used to irradiate the reaction gas flow was delivered through a waveguide. Microwave irradiation was continuous and the microwave intensity was adjusted using a connected power monitor. Optimal low reflection of the microwave radiation was achieved using the three-stub tuner. UV-meter sensors and the microwave generator were located on the right-hand side and left-hand side of the microwave cavity, respectively. A stirrer was installed on the back side in the reaction cavity (Figure 1) to enhance the transfer of microwave.

2.2. $\mathrm{TiO}_{2}$ Photocatalyst Balls. $\mathrm{TiO}_{2}$ film with anatase crystal structure was synthesized using a low pressure metal organic CVD method. Titanium tetraisopropoxide $\left(\mathrm{Ti}\left(\mathrm{OC}_{3} \mathrm{H}_{7}\right)_{4}\right.$, referred to as TTIP hereafter) was used as the precursor. Detailed information of the reactor was given elsewhere $[15,16]$. Argon gas was passed through a bubbler containing liquid TTIP and heated to $323 \mathrm{~K}$, to carry TTIP vapor to the reactor. Photocatalyst balls were prepared by depositing $\mathrm{TiO}_{2}$ film on alumina balls (Nikkato, HD-11, $\Phi 8 \mathrm{~mm}$ ).

2.3. Double Tube Type MDEML. $\mathrm{TiO}_{2}$ photocatalysts are excited by UV light, producing strong oxidants that can degrade organic compounds. Therefore, provision of UV is essential for the use of $\mathrm{TiO}_{2}$ photocatalysts. Typical UV lamps, however, have metal electrodes, which prevent them from being used in the microwave irradiation equipment. Therefore, a double tube type MDEML ( $170 \mathrm{~mm}$ length, $36 \mathrm{~mm}$ inner diameter, $55 \mathrm{~mm}$ outer diameter) that emits UV upon the irradiation of microwave was developed in this study. It was made of quartz to maximize the reaction efficiency. Small amount of mercury gas was doped between the tubes inside the double tube UV lamp that was kept vacuumed. The lamp used in this study is UV-C type lamp although UV-A and UV-B wavelength lights are emitted as well.

2.4. Evaluation of Reaction Activity. Experiments were performed to evaluate the degradation of HCFC-22 (Ulsan chemical Co., Ltd., 99.6\%) gas by using a flow type reactor 
under atmospheric pressure. The reactant gas was diluted with nitrogen and oxygen at the inlet of the reactor tube. Mass flow controllers modulated the flow rates of nitrogen and oxygen gases. The total flow rate of gas fed into the reactor was $300 \sim 700 \mathrm{cc} / \mathrm{min}$ and the oxygen concentrations in the gas were varied between 0 and $100 \mathrm{~mol} \%$. The decomposition rate was calculated from the difference between the HCFC22 concentrations measured at the reactor inlet and outlet as a function of residence time. The reactant gas was analyzed by gas chromatography (M600D, Younglin instrument Co., Ltd.) with a $6 \mathrm{ft}$ long Porapak Q column and a thermal conductivity detector. The oven temperature was programmed to change from $313 \mathrm{~K}(5 \mathrm{~min})$ to $433 \mathrm{~K}$ ( $3 \mathrm{~min})$, at a heating rate of $10^{\circ} \mathrm{C} / \mathrm{min}$. The concentration of HCFC-22 was obtained from the GC peak areas before and after reaction to calculate the decomposition rate.

\section{Results and Discussion}

3.1. Characteristics of the MDEML. Microwave discharge electrodeless lamps (MDELs), a unique light source, were first reported in 1968 [23]. The principle involved in MDELs is the absorption of high-frequency electromagnetic waves produced by a microwave generator by noble gases and vaporizable elements in the lamp, which results in UV emission. Mercury, sodium, sulfur, selenium, and cadmium can be used as vaporizable elements, whereas the noble gases are generally argon, neon, and krypton, among others. Compared with normal UV light sources, due to the absence of electrodes, MDELs do not produce blackened electrodes caused by wear and tear, oxidation, and sealing. In addition, MDELs have many advantages such as low price, low energy cost, high light intensity, and simple reactor. Moreover, there are many options for light-emitting materials so that MDELs can provide different wavelengths of UV radiation [24]. MDELs have been applied to disinfection of drinking water [25] and degradation of pollutants in water [26]. However, research on degradation of gaseous pollutants with MDELs is still scarcely reported.

The MDEML employed in this study has a stronger intensity than common mercury lamps, especially in UV range. The ultraviolet and visible wavelengths emitted were detected by a UV/Vis-spectrometer (AVASPEC-2048, Avantes Co., Ltd.). The sensor of the UV/Vis-spectrometer was installed on the right-hand-side port of the microwave cavity. The distance between MDEML and the sensor was about $30 \mathrm{~cm}$. The emission wavelengths of MDEML distributed widely in the range of $180 \sim 600 \mathrm{~nm}$ were $254,297,311,365,404,435,547$, and $579 \mathrm{~nm}$. The MDEML containing a mixture of mercury and argon showed mainly atomic $\mathrm{Hg}$ emission lines at $253.7 \mathrm{~nm}\left(6^{2} \mathrm{P}_{1}-6^{2} \mathrm{~S}_{0}\right)$. The influence of microwave power on the UV spectrum emitted from the MEDML was examined. Figure 2 shows the UV spectrum emitted from MEDML with different input microwave intensities measured. UVC $(254 \mathrm{~nm})$ intensity was high even at the lowest power $(0.2 \mathrm{~kW})$, increasing slowly with the input microwave power. On the contrary, the intensities of UV-A $(365 \mathrm{~nm})$ and UV-B $(297 \mathrm{~nm})$ were very low at low input microwave power, but

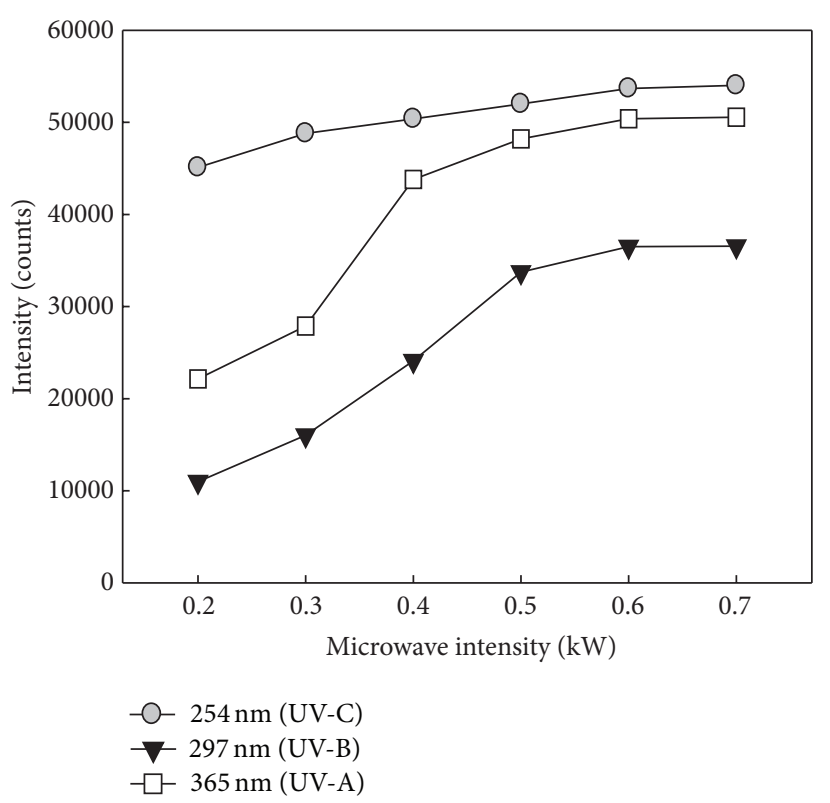

FIgURE 2: Change of the UV intensities radiated at different microwave intensities.

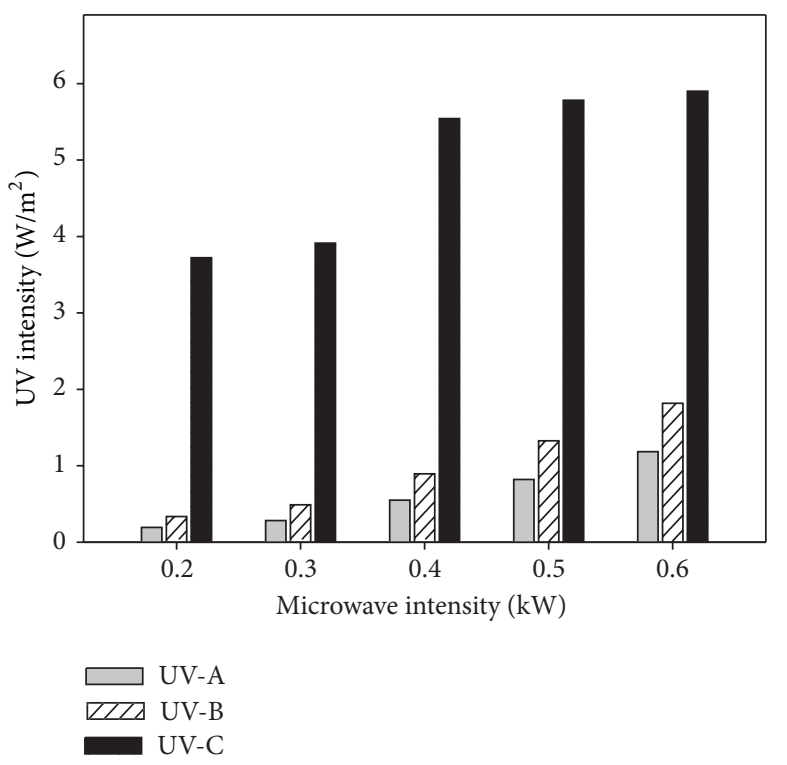

FIGURE 3: Comparison of the UV irradiances measured at different microwave intensities.

they increased rapidly with increasing microwave power. All the three UV waves showed little change in their intensity above $0.6 \mathrm{~kW}$ of microwave power.

Another measurement made in this study was the irradiance $\left(\mathrm{W} / \mathrm{m}^{2}\right)$ at each $\mathrm{UV}$ wavelength range. A UV radiometer (HD2102-2, Delta OHM) was used for measuring this quantity. Figure 3 compares the UV irradiance measured at different microwave intensities. The sensor of the UV radiometer was installed on the right-hand-side port of the microwave cavity (Figure 1). The distance between MDEML and the sensor was about $30 \mathrm{~cm}$. The ranges of wavelength 


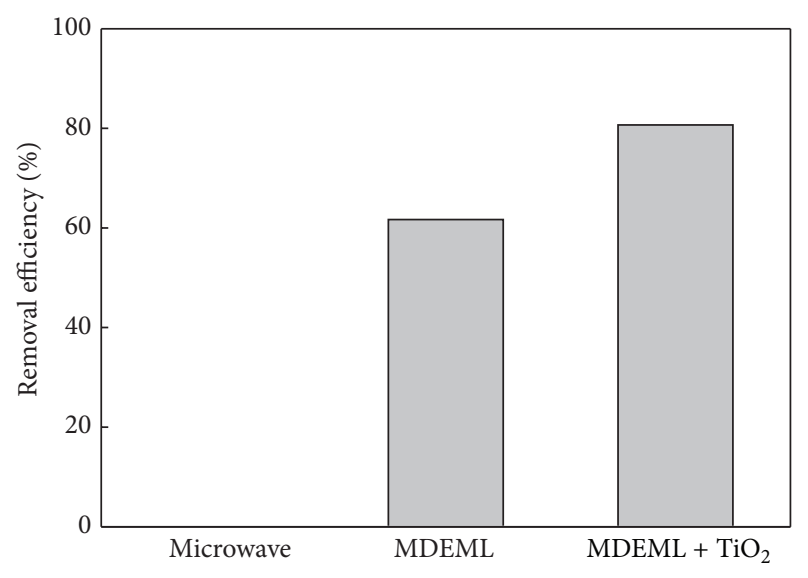

Figure 4: Degradation efficiencies obtained under different experimental conditions.

detected by UV-A, UV-B, and UV-C sensors are 315 400 nm, $280 \sim 315 \mathrm{~nm}$, and $220 \sim 280 \mathrm{~nm}$, respectively. It is shown in Figure 3 that the UV irradiation from the MDEML used in this study is dominated by short wave UV with high energy. At all microwave intensities tested in this study, UV-C exhibited much larger irradiance than UV-A and UV-B. The UV-A and UV-B irradiances increased with the microwave power, whereas the UV-C energy showed little change at microwave power larger than $0.4 \mathrm{~kW}$. This result is in agreement with the result shown in Figure 2.

\subsection{The Effects of the Technological Convergence. Figure 4} compares the conversion of HCFC-22 by photocatalytic degradation at various experimental conditions. The experiments were carried out with the total flow rate of $500 \mathrm{cc} / \mathrm{min}$, the HCFC-22 inlet concentration of $20 \%$, and the microwave power of $0.4 \mathrm{kw}$. When only microwave was irradiated without the use of MDEML, removal of HCFC-22 did not take place. When MDEML was used without $\mathrm{TiO}_{2}$ photocatalysts balls, the degradation efficiency was $62 \%$. The highest degradation efficiency (81\%) was obtained when both $\mathrm{TiO}_{2}$ photocatalysts balls and MDEML were used. The difference between the results of MU and MUP was 19\%, which indicates that the contribution of photocatalysis accounted for $23.5 \%$ of the total degradation. In this study, microwave was additionally irradiated on the conventional photocatalysis system for pollutant degradation expecting a synergy effect that activates reactants and promotes oxidation reactions. The experimental results showed that a higher microwave intensity led to a higher degradation efficiency. The effect of microwave on the oxidation of reactants and intermediate products, however, was not observed in the experiments. The addition of oxygen was expected to contribute to production of active oxidants when oxygen was irradiated by microwave, but it turned out not to be true. Therefore, additional experiments are needed in the future expecting a synergy effect by adding more powerful oxidants such as ozone.
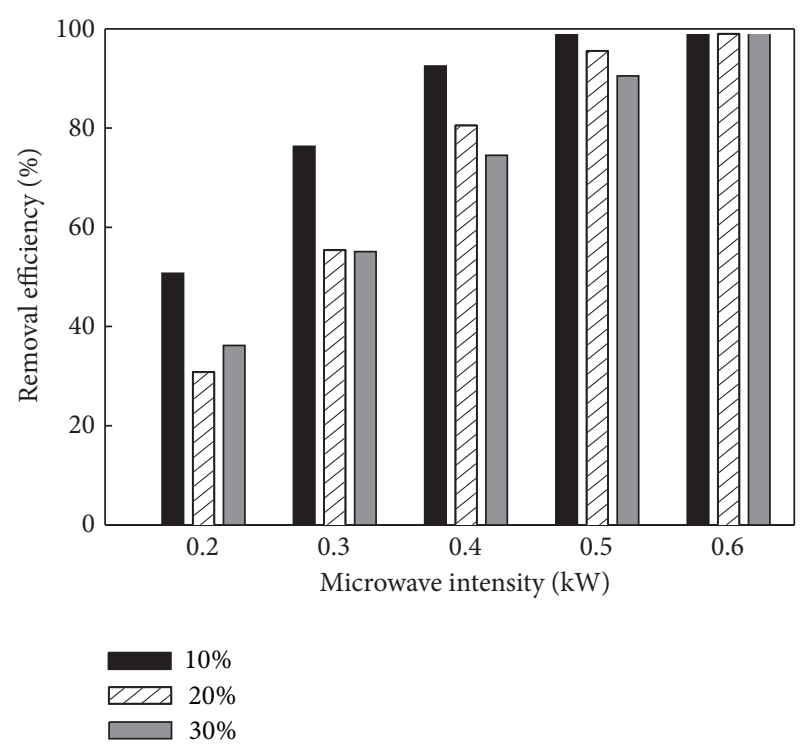

FIGURE 5: Effect of inlet concentration on photocatalytic removal efficiency of HCFC-22.

3.3. Photocatalytic Degradationof HCFC-22. The influence of the inlet concentration of HCFC-22 on its photocatalytic removal efficiency was investigated. Figure 5 shows the ratio of the outlet concentration over the inlet concentration of HCFC-22 measured as a function of microwave power with different inlet concentrations: $10 \%, 20 \%$, and $30 \%$. Total gas flow rate was $500 \mathrm{cc} / \mathrm{min}$ and pure oxygen was provided as the carrier gas. The removal efficiency of HCFC-22 was highest when the inlet concentration was $10 \%$. Despite no significant differences in the removal efficiency were observed when the inlet concentration was changed from $20 \%$ to $30 \%$, the little differences observed for these two concentrations show that, in most of experimental conditions, the removal efficiency decreases when the inlet concentration increases. It is known that, generally, photocatalysis is known to exert high efficiency at low concentrations $[7,16]$, which agrees with the result of this study. On the one hand, it is clearly shown in this figure that the removal efficiency increases with microwave intensity.

Reactor residence time, which is determined by the gas flow rate, is the duration of stay in the reactor (from the entry and to the exit) of exhaust gas. The results shown in Figure 6 were achieved with the inlet HCFC-22 concentration of $20 \%$ and the oxygen concentration of $80 \%$. As presented, with the residence time increasing from $20 \mathrm{sec}$ to $47 \mathrm{sec}$, the decomposition efficiency of HCFC-22 increased, caused by increase in both collision time and collision possibility. Therefore, gas residence time is a key point of photocatalytic decomposition in the experiments. Generally, a longer residence time results in a higher removal efficiency. However, if the residence time is too long, the amount of exhaust gas treated in unit time decreases, which results in a low energy efficiency and high energy cost. Therefore, when microwave/UV/TiO 2 photocatalysts hybrid process is used, the residence time should be determined by comprehensively taking into account the inlet 

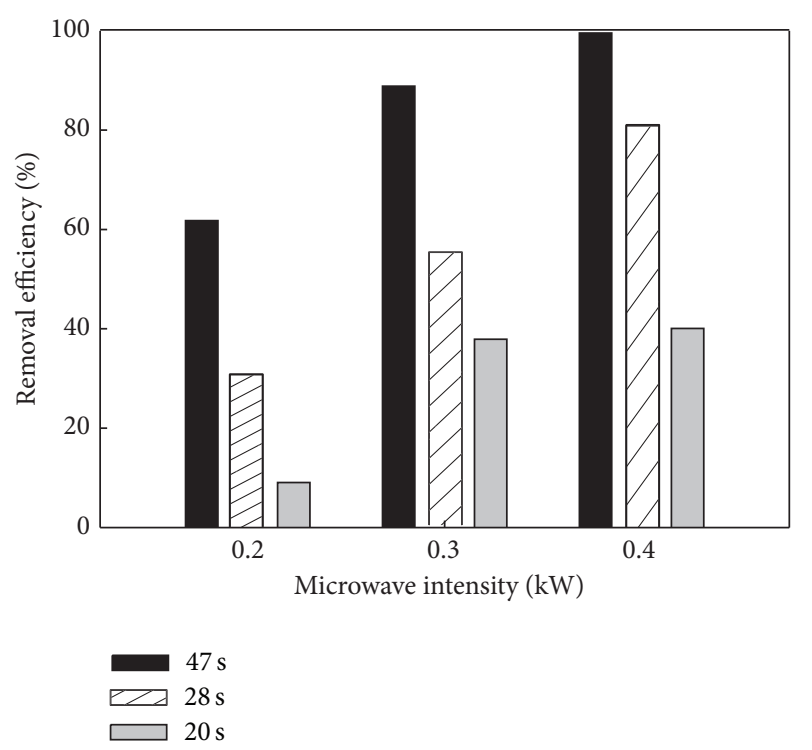

FIGURE 6: Effect of reaction residence time on photocatalytic removal efficiency of HCFC-22.

concentration, volume of degradation, capacity of devices, and admitted costs.

The influence of the concentration of oxygen, which plays a role as an oxidant in the photocatalytic removal of HCFC-22, on the removal efficiency was also investigated in this study. Figure 7 shows the removal efficiency obtained with different oxygen-nitrogen ratios in the carrier gas as a function of microwave power. The total gas flow rate was $500 \mathrm{cc} / \mathrm{min}$ and the inlet HCFC-22 concentration was $20 \%$. HCFC-22 removal efficiency increased with increasing microwave power on every oxygen concentration tested. It also increased with increasing oxygen concentration at every microwave power tested. In particular, the removal efficiency was $100 \%$ when the microwave intensity of $0.3 \mathrm{~kW}$ was applied at the oxygen concentration of $100 \%$ or when the microwave intensity of $0.4 \mathrm{~kW}$ was applied at the oxygen concentration of $40 \%$ or higher. This result indicates that the microwave power and the carrier gas composition should be determined with the consideration of the concentration of HCFC-22 and the operation cost.

\section{Conclusions}

The following conclusions were inferred from the results of photocatalytic degradation of HCFC-22 using microwave/UV/ $\mathrm{TiO}_{2}$ hybrid process.

(1) The MDEML used in this study showed mainly atomic $\mathrm{Hg}$ emission lines at $253.7 \mathrm{~nm}$. At all microwave powers tested, UV-C exhibited much larger irradiance than UV-A and UV-B.

(2) When MDEML was used without $\mathrm{TiO}_{2}$ balls, the degradation efficiency was $62 \%$. The highest degradation efficiency $(81 \%)$ was obtained when both $\mathrm{TiO}_{2}$ balls and MDEML were used.

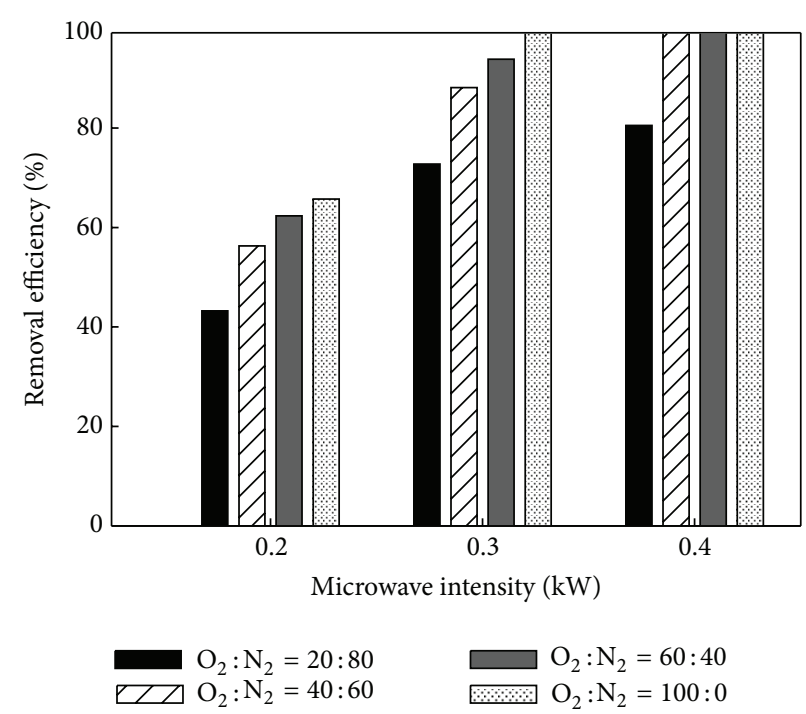

FIgURE 7: Effect of carrier gas composition on degradation of HCFC-22.

(3) With increasing microwave power, the degradation efficiency of HCFC-22 increased and the degradation efficiency was highest when the inlet concentration was lowest.

(4) The degradation efficiency of HCFC-22 increased with the residence time due to increased collision time and collision possibility. Because the energy cost also increases with residence time, the residence time should be determined by comprehensively taking into account the inlet concentration, volume of degradation, capacity of devices, and admitted costs.

(5) The microwave power and the carrier gas composition should be determined with the consideration of the concentration of HCFC-22 and the operation cost.

\section{Conflict of Interests}

The authors declare that there is no conflict of interests regarding the publication of this paper.

\section{Acknowledgment}

This research was supported by Basic Science Research Program of the National Research Foundation of Korea (NRF) funded by the Ministry of Education (2013R1A1A2A10004797).

\section{References}

[1] M. J. Molina and F. S. Rowland, "Stratospheric sink for chlorofluoromethanes: chlorine atom catalysed destruction of ozone," Nature, vol. 249, no. 5460, pp. 810-812, 1974.

[2] J. S. Nimitz and S. R. Skaggs, "Estimating tropospheric lifetimes and ozone-depletion potentials of one- and two-carbon hydrofluorocarbons and hydrochlorofluorocarbons," Environmental Science \& Technology, vol. 26, no. 4, pp. 739-744, 1992. 
[3] R. Talukdar, A. Mellouki, T. Gierczak, J. B. Burkholder, S. A. McKeen, and A. R. Ravishankara, "Atmospheric fate of difluoromethane, 1,1,1-trifloroethane, pentafluoroethane, and 1,1-dichloro-1-fluoroethane: rate coefficients for reactions with hydroxyl and UV absorption cross sections of 1,1-dichloro-1fluoroethane," The Journal of Physical Chemistry, vol. 95, no. 15, pp. 5815-5821, 1991.

[4] M. McFarland and J. Kaye, "Chlorofluorocarbons and ozone," Photochemistry and Photobiology, vol. 55, no. 6, pp. 911-929, 1992.

[5] T. Oyama and K. Otani, "Conversion of freon to $\mathrm{Cl}_{2}$ and teflonlike compounds," Kagaku to Kogyo, vol. 4, p. 631, 1993.

[6] W. H. Glaze, J. W. Kang, and D. H. Chapin, "Advanced oxidation processes for treating groundwater contaminated with TCE and PCE: laboratory studies," Journal of the American Water Works Association, vol. 80, no. 5, pp. 57-63, 1988.

[7] R. Hoffmann, S. T. Martin, W. Y. Choi, and D. W. Bahnemann, "Environmental applications of semiconductor photocatalysis," Chemical Reviews, vol. 95, no. 1, pp. 69-96, 1995.

[8] M. V. B. Zanoni, J. J. Sene, and M. A. Anderson, "Photoelectrocatalytic degradation of Remazol Brilliant Orange 3R on titanium dioxide thin-film electrodes," Journal of Photochemistry and Photobiology A: Chemistry, vol. 157, no. 1, pp. 55-63, 2003.

[9] X. Quan, S. Chen, J. Su, J. Chen, and G. Chen, "Synergetic degradation of 2,4-D by integrated photo- and electrochemical catalysis on a $\mathrm{Pt}$ doped $\mathrm{TiO}_{2} / \mathrm{Ti}$ electrode," Separation and Purification Technology, vol. 34, no. 1-3, pp. 73-79, 2004.

[10] R. W. Matthews, "Photo-oxidation of organic material in aqueous suspensions of titanium dioxide," Water Research, vol. 20, no. 5, pp. 569-578, 1986.

[11] N. Venkatachalam, M. Palanichamy, and V. Murugesan, "Solgel preparation and characterization of nanosize $\mathrm{TiO}_{2}$ : its photocatalytic performance," Materials Chemistry and Physics, vol. 104, no. 2-3, pp. 454-459, 2007.

[12] E. Dorjpalam, M. Takahashi, Y. Tokuda, and T. Yoko, "Controlling carrier density and its effect on I-V characteristics of the anatase- $\mathrm{TiO}_{2}$ thin films prepared by a sputter deposition method," Thin Solid Films, vol. 483, no. 1-2, pp. 147-151, 2005.

[13] S. C. Jung, S. J. Kim, N. Imaishi, and Y. I. Cho, "Effect of $\mathrm{TiO}_{2}$ thin film thickness and specific surface area by low-pressure metal-organic chemical vapor deposition on photocatalytic activities," Applied Catalysis B: Environmental, vol. 55, no. 4, pp. 253-257, 2005.

[14] S. C. Jung, B. H. Kim, S. J. Kim, N. maishi, and Y. I. Cho, "Characterization of $\mathrm{a} \mathrm{TiO}_{2}$ photocatalyst film deposited by CVD and its photocatalytic activity," Chemical Vapor Deposition, vol. 11, no. 3, pp. 137-141, 2005.

[15] S. C. Jung, "Photocatalytic activities and specific surface area of $\mathrm{TiO}_{2}$ films prepared by CVD and sol-gel method," Korean Journal of Chemical Engineering, vol. 25, no. 2, pp. 364-367, 2008.

[16] Y. S. Bae and S. C. Jung, "A study of the photocatalytic destruction of propylene using microwave discharge electrodeless lamp," Journal of Industrial and Engineering Chemistry, vol. 16, no. 6, pp. 947-951, 2010.

[17] V. Cirkva and M. Hájek, "Microwave photochemistry. Photoinitiated radical addition of tetrahydrofuran to perfluorohexylethene under microwave irradiation," Journal of Photochemistry and Photobiology A: Chemistry, vol. 123, no. 1-3, pp. 21-23, 1999.
[18] J. Literak and P. Klan, “The electrodeless discharge lamp: a prospective tool for photochemistry: part 2. Scope and limitation," Journal of Photochemistry and Photobiology A: Chemistry, vol. 137, no. 1, pp. 29-35, 2000.

[19] S. Horihoshi, H. Hidaka, and N. Serpone, "Environmental remediation by an integrated microwave/UV-illumination method. 1. Microwave-assisted degradation of rhodamine-B dye in aqueous $\mathrm{TiO}_{2}$ dispersions," Environmental Science \& Technology, vol. 36, no. 6, pp. 1357-1366, 2002.

[20] S. Horihoshi, H. Hidaka, and N. Serpone, "Environmental remediation by an integrated microwave/UV-illumination technique: IV. Non-thermal effects in the microwave-assisted degradation of 2,4-dichlorophenoxyacetic acid in UVirradiated $\mathrm{TiO}_{2} / \mathrm{H}_{2} \mathrm{O}$ dispersions," Journal of Photochemistry and Photobiology A: Chemistry, vol. 159, no. 3, pp. 289-300, 2003.

[21] S. C. Jung, "The microwave-assisted photo-catalytic degradation of organic dyes," Water Science \& Technology, vol. 63, no. 7, pp. 1491-1498, 2011.

[22] S. J. Kim, S. C. Kim, S. G. Seo et al., "Photocatalyzed destruction of organic dyes using microwave/ $\mathrm{UV} / \mathrm{O}_{3} / \mathrm{H}_{2} \mathrm{O}_{2} / \mathrm{TiO} \mathrm{O}_{2}$ oxidation system," Catalysis Today, vol. 164, no. 1, pp. 384-390, 2011.

[23] J. M. Mansfiel, M. P. Bratzel, H. O. Norgordo, D. O. Knapp, K. E. Zacha, and J. D. Wineford, "Experimental investigation of electrodeless discharge lamps as excitation sources for atomic fluorescence flame spectrometry," Spectrochimica Acta B: Atomic Spectroscopy, vol. 23, no. 6, pp. 389-402, 1968.

[24] P. Muller, P. Klan, and V. Cirkva, "The electrodeless discharge lamp: a prospective tool for photochemistry: part 5: fill material-dependent emission characteristics," Journal of Photochemistry and Photobiology A: Chemistry, vol. 171, no. 1, pp. 51-57, 2005.

[25] B. Henry, I. Tatiana, S. Kristin, and B. Karel, "New UV irradiation and direct electrolysis-promising methods for water disinfection," Chemical Engineering Journal, vol. 85, no. 2-3, pp. 111-117, 2002.

[26] C.-H. Wu, "Effects of operational parameters on the decolorization of C.I. Reactive Red 198 in UV/TiO 2 -based systems," Dyes and Pigments, vol. 77, no. 1, pp. 31-38, 2008. 

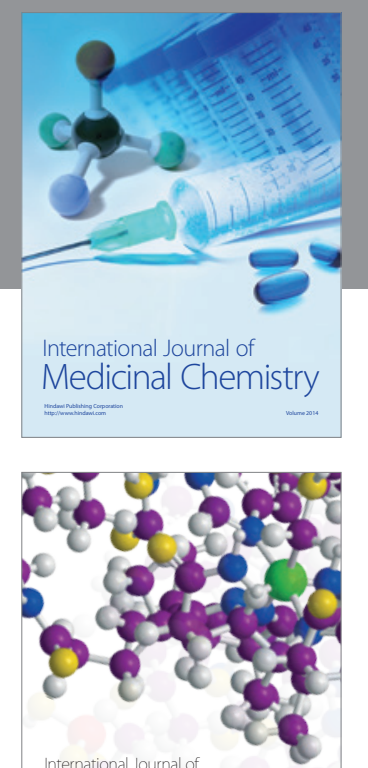

\section{Carbohydrate} Chemistry

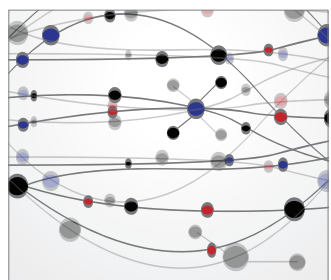

The Scientific World Journal
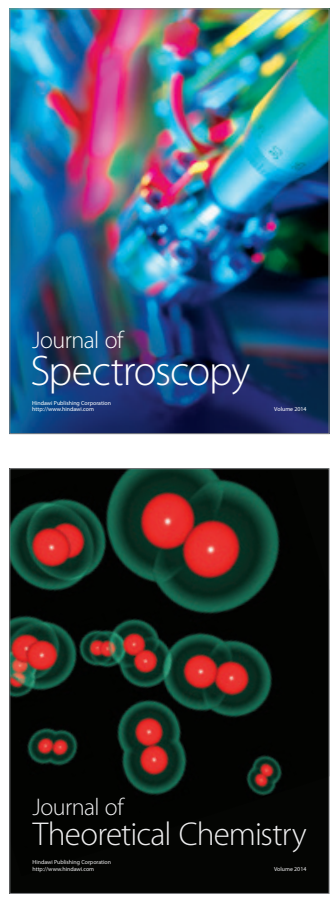
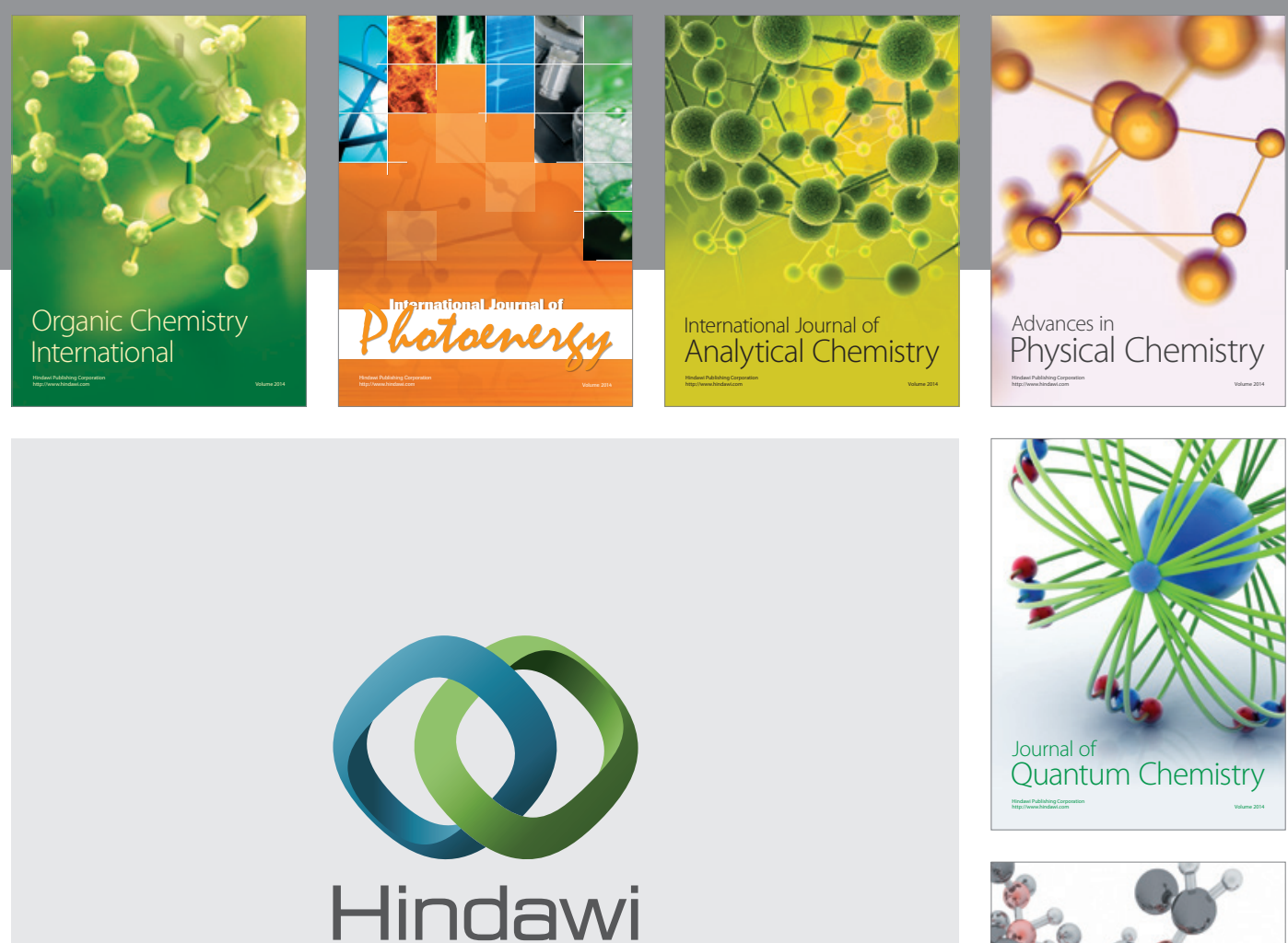

Submit your manuscripts at

http://www.hindawi.com

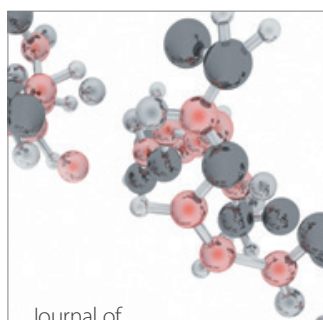

Analytical Methods

in Chemistry

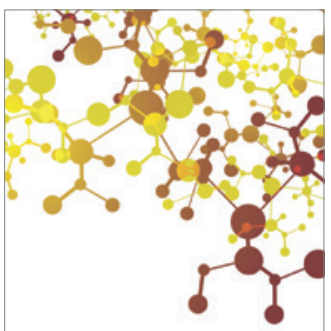

Journal of

Applied Chemistry

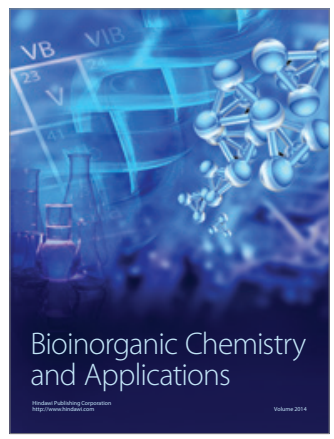

Inorganic Chemistry
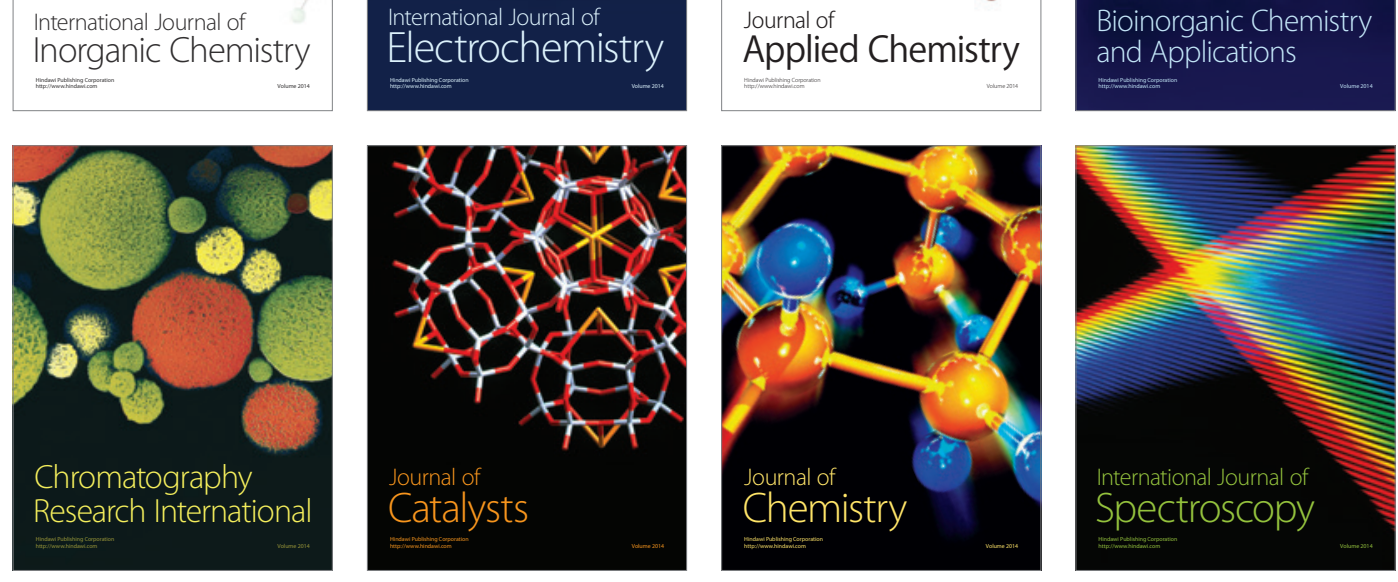